Research Article

\title{
Preparation and Characterization of Antimony-Doped Tin Oxide Nanocrystallite Coatings on 316L Stainless Steel
}

\author{
Giang Nguyen Truong, ${ }^{1}$ Long Hoang Vinh, ${ }^{1}$ Suong Huynh Thu, ${ }^{2}$ \\ Phuong Nguyen Thi Hong $\mathbb{D}^{2}$, and Bac Nguyen Quang $\mathbb{D}^{2}$ \\ ${ }^{1}$ Department of Chemistry, Faculty of Materials, National University of Civil Engineering, No. 55 Giai Phong Rd., Hanoi, \\ Vietnam \\ ${ }^{2}$ School of Chemical Engineering, Hanoi University of Science and Technology, No. 1 Dai Co Viet St., Hanoi, Vietnam
}

Correspondence should be addressed to Phuong Nguyen Thi Hong; phuong.nguyenthihong@hust.edu.vn and Bac Nguyen Quang; bac.nguyenquang@hust.edu.vn

Received 15 August 2021; Revised 18 October 2021; Accepted 26 October 2021; Published 3 November 2021

Academic Editor: Thi Anh Huong Nguyen

Copyright $\odot 2021$ Giang Nguyen Truong et al. This is an open access article distributed under the Creative Commons Attribution License, which permits unrestricted use, distribution, and reproduction in any medium, provided the original work is properly cited.

\begin{abstract}
The study on the coatings containing antimony-dope tin oxide mostly has been done on titanium and its alloys for preparation of electrode materials. In this study, we try to prepare the similar coatings on 316L stainless steel, which is more common than titanium, and investigate some characteristics of the formed coatings. The preparation of the coating is by the impregnation of the substrate in solution containing $\mathrm{SnCl}_{4}$ and $\mathrm{SbCl}_{3}$ with the ratio of $93 / 7$, and the concentration of $\mathrm{SbCl}_{3}, 10 \mathrm{~g} / \mathrm{L}$ in isopropanol, $\mathrm{pH}$ of 1-1.2, and the annealed temperature of $450^{\circ} \mathrm{C}$ give suitable coating for electrode materials. Some coating features, such as the crystal structure (XRD), morphology (SEM), hardness, electrical resistant, and electrochemical behaviors of the coating on the substrate have been also investigated. The results of the study show that the coatings can be used as electrode materials for the effective treatment of organic colorants in water such as methylene blue in water treatment.
\end{abstract}

\section{Introduction}

The mixed metal oxides on metal substrate attracted many researchers due to their scientific meanings and possible applications [1]. The $\mathrm{SnO}_{2}$ coatings doped with $\mathrm{Sb}$ have been studied and applied as an anode electrode in color wastewater treatment especially on titanium metal substrate [2-6]. In the system of Sb-doped $\mathrm{SnO}_{2}$ coatings on titanium, the crack-mud phenomenon, i.e., the crack of the coatings during drying and heat treatment, often occurred that makes the life of the electrode potentially reduced due to the electrolyte permeation through cracks or coating damage [3].

Stainless steel alloys are more common than titanium, with high mechanical strength, high chemical resistance, and good electrical conductivity, and they can be used as the substrate for coating and preparation of electrode materials. However, to the best of our knowledge, the investigation and application of antimony-doped tin oxide coatings on high steel alloys are extremely rare. In this study, the preparation and characterization of Sb-doped $\mathrm{SnO}_{2}$ coatings on 316L stainless steel will be investigated in detail. The coatings were prepared by impregnating the substrates into a solution containing $\mathrm{SnCl}_{4}$ and $\mathrm{SbCl}_{3}$ and then annealed at designated temperature. The morphology and crystallinity of the coatings were determined by scanning electron microscopy (SEM) and X-ray diffraction (XRD). The electrochemical properties of this electrode were studied by cyclic voltammetry. The coating has been applied as the anode for the electrochemical degradation of methylene blue in solution.

\section{Experimental}

2.1. Reagents and Materials. Tin tetrachloride pentahydrate $\left(\mathrm{SnCl}_{4} \cdot \mathrm{H}_{2} \mathrm{O} 98.0 \%\right)$, antimony chloride $\left(\mathrm{SbCl}_{3}\right)$, isopropanol, $\left(\mathrm{C}_{3} \mathrm{H}_{8} \mathrm{O}, 99.5 \%\right)$, and hydrochloric acid $(\mathrm{HCl}, 37 \%)$ are all 
from Sigma Aldrich for experiments. Acetone $\left(\mathrm{C}_{3} \mathrm{H}_{6} \mathrm{O}\right.$, 99.7\%, Xylong, China) is used for cleaning electrode. All chemicals are used as received without any further purification.

Samples of commercial 316L stainless steel with the reported composition of $\mathrm{C}(\leq 0.03 \%), \mathrm{Mn}(\leq 2 \%), \mathrm{P}$ $(\leq 0.045 \%), \mathrm{S}(\leq 0.03 \%), \mathrm{Si}(\leq 1 \%), \mathrm{Cr}(16-18 \%)$, Ni $(10-14 \%)$, Mo (2-3\%), and iron in balance are supplied by Chau Duong International Industrial Co., Ltd.

2.2. The Preparation of the Electrode. The 316L stainless steel plates with a size of $12 \times 12 \times 2 \mathrm{~mm}$ were polished with abrasive papers, cleansed with water and acetone, and then dried. The coating solution was prepared by dissolving $132.86 \mathrm{~g} \mathrm{SnCl}_{4} .5 \mathrm{H}_{2} \mathrm{O}$ and $\mathrm{SbCl}_{3}(0-15 \mathrm{~g})$ in isopropanol, $\mathrm{pH}$ of the solution was adjusted to $0.8-1.2$ by concentrated hydrochloric acid, and then diluted into $1 \mathrm{~L}$ of solution with isopropanol. The prepared solution is heated to about $90^{\circ} \mathrm{C}$, and then, the samples are dipped for 2 minutes, dried, and calcined at designated temperatures from 250 to $600^{\circ} \mathrm{C}$ in a muffle oven for an hour. This procedure was repeated 6 times to obtain a suitable coating thickness. Finally, the electrode was annealed for 5 hours in the final step to induce crystallization of oxide mixture.

2.3. Characterization and Analysis Methods. The crystal structure and compositions of the coating film were studied by an X-ray diffractometer (XPERT PRO, Netherlands) using $\mathrm{CuK} \alpha$ radiation in the $2 \theta$ range of $20^{\circ}-70^{\circ}$. The surface morphology of the metal oxide coating and the qualitative analysis of elements present in the coatings were measured on scanning electron microscopy (SEM, JEOL, JSM-7600F, US).

The resistivity of the film was measured by the fourprobe method. Electrochemical properties of the formed film were investigated by open circuit potential measurement vs. time and potentiodynamic polarization curves in the $2 \mathrm{~g} / \mathrm{L} \mathrm{Na}_{2} \mathrm{SO}_{4}$ solution at room temperature. The electrochemical measurements were conducted on a threeelectrode electrochemical system (Autolab PGSTAT 302N, Netherlands) with the prepared electrode served as the working electrode, $\mathrm{Pt}$ mesh as the counter electrode and a saturated calomel electrode as the reference electrode. The working electrode potentials were scanned from $-0.5 \mathrm{~V}$ to $+1.5 \mathrm{~V}$ versus open circuit potential with a scanning rate of $5 \mathrm{mV} / \mathrm{s}$ for potentiodynamic polarization measurement.

The UV-Vis absorption behavior of the MB solution is measured on a Cary 100 equipment, recorded from $300 \mathrm{~nm}$ to $800 \mathrm{~nm}$ at room temperature. Discoloration efficiency in methylene blue (MB) solution treatment is evaluated as the relative peak area calculated from 450 to $750 \mathrm{~nm}$ from the $\mathrm{UV}-\mathrm{Vis}$ spectra.

\section{Results and Discussion}

3.1. Effect of Different Annealing Temperatures on Coating Structure and Surface Morphology. The formation of the coating is completed when the deposited is annealing. The heat treatment is chosen to decompose the reactants on the substrate. The formation of the coating will depend on the decomposition of the precursors and the interaction of the particles. The results of the crystal structure investigation of the coating with the various annealing temperature are shown in Figure 1.

Figure 1 shows that the phase of the coating on the substrate is almost the same as the one of $\mathrm{SnO}_{2}$ when the samples are annealed at various temperatures from 350 to $450^{\circ} \mathrm{C}$. At high annealing temperature, such as $600^{\circ} \mathrm{C}$, chromium oxide phase (JCPDS 84-1616) and mixture of nickel and iron oxides are formed as indicated by the presence of different peaks from two theta of $20-70^{\circ}$. The peaks for iron oxides are very weak or unclear, probably because of its fluorescence, so that the suitable temperature for heat treatment will be around $450^{\circ} \mathrm{C}$.

The XRD patterns also show that the crystallinity of the coating may not be very high as indicated by low intensity of most XRD peaks and the noise of the background. The small crystal may favor the formation of the smooth surface when coated with the amorphous portion.

It is noted that the presence of the $\mathrm{Sb}$ species on the coating is not indicated by the XRD data due to the incorporation of the $\mathrm{Sb}$ species on the $\mathrm{SnO}_{2}$ structure host. Only a small peak at around $51^{\circ}$ is assigned to the one of $\mathrm{Sb}_{2} \mathrm{O}_{3}$. The higher the annealing temperature, the lower the peak of $\mathrm{Sb}_{2} \mathrm{O}_{3}$, probably due to the formation of antimonite or antimonate rather than the oxide of antimony. Because the ionic radii of $\mathrm{Sb}$ and $\mathrm{Sn}$ are rather close, the partial replacement of $\mathrm{Sn}$ by $\mathrm{Sb}$ may occur to some extent as expected, and some properties of the coating will be improved such as the coating conductivity, via supra.

The qualitative analysis and the evaluation of coating composition are further investigated by the EDX measurement. The results of the analysis on the surface of the samples annealed at 350,450 , and $600^{\circ} \mathrm{C}$ are shown in Figure 2.

Figure 2 and the corresponding analysis inset confirm the presence of $\mathrm{Sn}$ and $\mathrm{Sb}$ in the samples. The presence of the iron, nickel, and chromium species may come from the substrate materials. When the samples are impregnated into high acidity solutions, some of the materials may be dissoluted and deposited back to the coating. The data analysis shows that the ratio of $\mathrm{Sn}$ and $\mathrm{Sb}$ is not perfectly the same as the one in the doping solution probably due to the peak positions of $\mathrm{Sn}$ and $\mathrm{Sb}$ elements are rather close in the EDX spectra, so the evaluation of elemental composition will only give rough numbers.

When the sample is annealed at $600^{\circ} \mathrm{C}$, the composition of the coating is totally different from that of the lower one. The analysis data showed that the $\mathrm{Sn}$ and Sb contents in the coating are only few percent, and the coating composes mostly of iron, chromium, and nickel oxides. These results are consistent with the results of phase analysis. It means that the beneath layer on the substrate has been corroded or destroyed when dipping or heating the samples.

The morphology of the samples treated at various temperatures is also studied. The photos of the SEM measurement of the bare substrate and the coatings annealed at 350,450 , and $600^{\circ} \mathrm{C}$ are shown in Figure 3. 


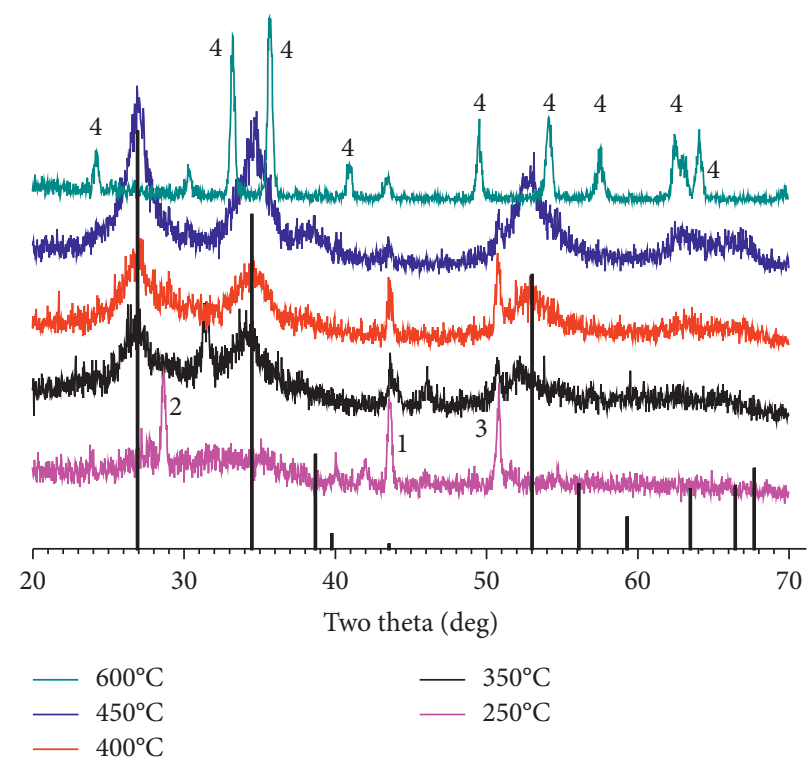

FIGURE 1: $\mathrm{XRD}$ patterns of $\mathrm{SnO}_{2}$-doped $\mathrm{Sb}$ coatings on 316L stainless steel at various annealing temperatures. The peaks of $\mathrm{SnO}_{2}$ (adapted from [7]) are presented as the vertical black bars and 1, $\mathrm{NiO}$ (JCPDS 78-0643); $2, \mathrm{Sb}_{2} \mathrm{O}_{3}$ (JCPDS 42-1466); 3, $\mathrm{Sb}_{2} \mathrm{O}_{4}$ (JCPDS 37-0854); 4, $\mathrm{Cr}_{2} \mathrm{O}_{3}$ (JCPDS 84-1616).

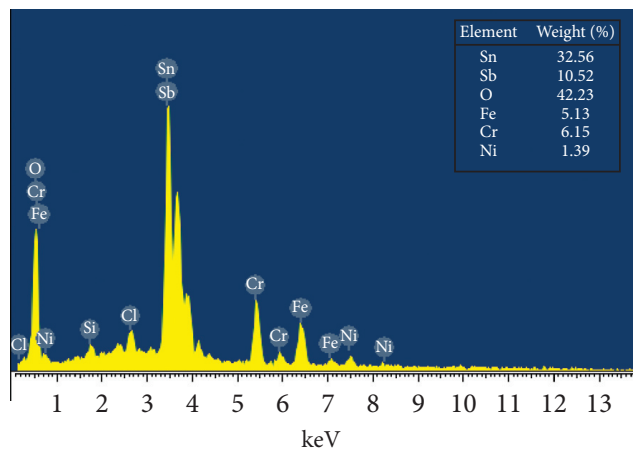

(a)

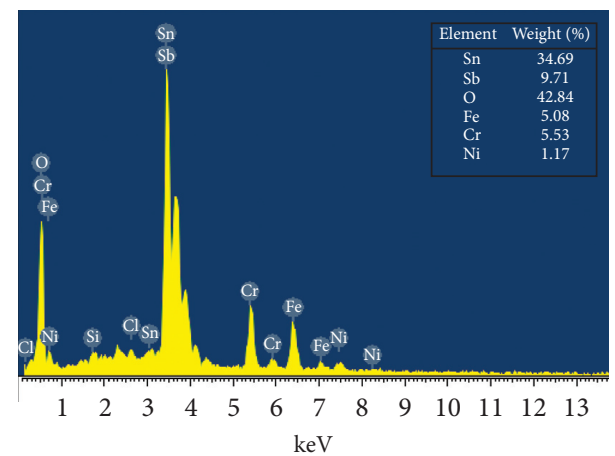

(b)

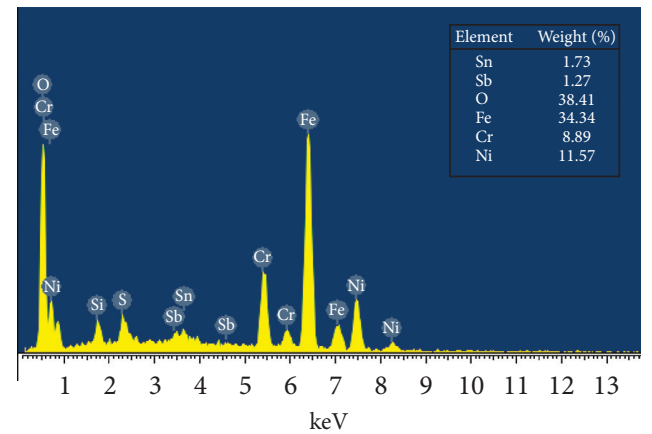

(c)

Figure 2: EDX patterns of Sb-doped $\mathrm{SnO}_{2}$ coatings on $316 \mathrm{~L}$ stainless steel at various annealing temperatures: (a) $350^{\circ} \mathrm{C}$; (b) $450^{\circ} \mathrm{C}$, and (c) $600^{\circ} \mathrm{C}$.

The SEM images in Figure 3 show that the original substrate has a smooth surface, the deposition of the materials on the surface is clear, and the coating morphology is very different from that of the substrate.
At $350^{\circ} \mathrm{C}$, the coatings seem to coarse with the formation of large particles with clear edges. The array of the particles makes the coating difficult to be dense to completely cover the substrate surface. Mechanical properties of the coating 


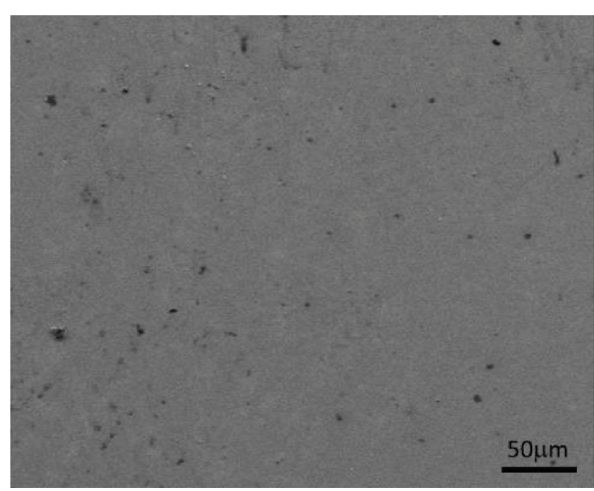

(a)

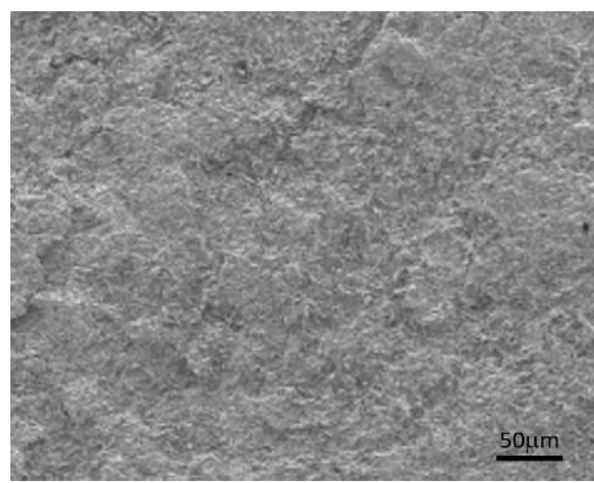

(c)

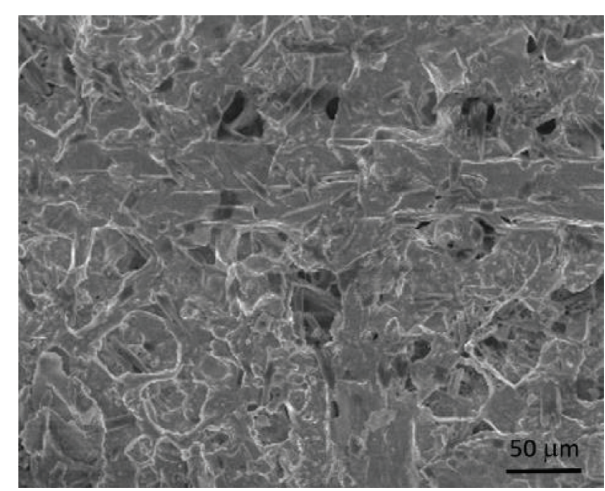

(b)

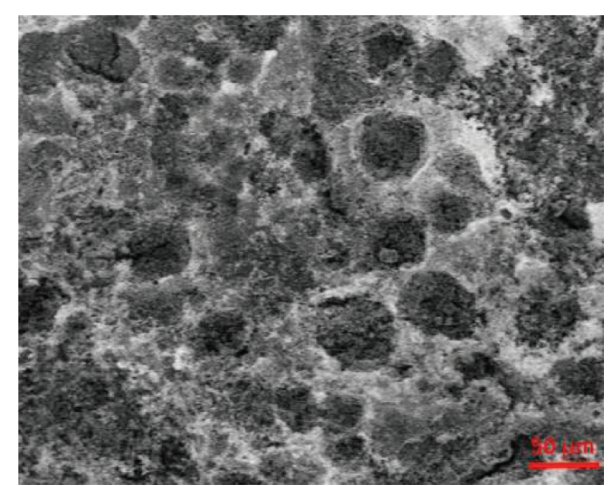

(d)

Figure 3: The SEM images of the $\mathrm{SnO}_{2}$-doped $\mathrm{Sb}$ thin films on (a) $316 \mathrm{~L}$ stainless steel, (b) $350^{\circ} \mathrm{C}$ annealing (c), $450^{\circ} \mathrm{C}$ annealing (d), and $600^{\circ} \mathrm{C}$ annealing.

are rather poor. When the samples anneal at $450^{\circ} \mathrm{C}$, the surface of the coating is very smooth. No large particles or grain boundaries are observed, and its physicochemical properties are also improved which maybe suitable for the applications of electrode materials.

The case of the samples annealed at $600^{\circ} \mathrm{C}$, and the surface of the samples becomes inhomogeneity with the formation of large lumps of material next to some white ones. The coating seems to be burned out and easily removed from the surface with mechanical force. From the basic structure, composition, and morphology of the coating, it is clear that the suitable annealing temperature is around $450^{\circ} \mathrm{C}$ and should not be heated to $600^{\circ} \mathrm{C}$ or higher.

3.2. Effect of pH Solution on Coating Structure and Surface Morphology. The composition of the dipping solution will influence to the formation and properties of the coating on the substrate surface. The investigation of the $\mathrm{pH}$ of the solution on the crystal structure of the coating has been done, and the results are shown in Figure 4.

The results of XRD measurements on the prepared coatings show that at $\mathrm{pH} 0.8$, the coatings are very poor and due to the corrosion of the substrate layer by acid, which may favor the exfoliation of the coatings. The products of corrosion such as iron or other ingredient compounds may be incorporated into the coatings.
At higher $\mathrm{pH}$ values of the dipping solution such as $\mathrm{pH}=1$ or 1.2 , the coating is formed with high quality and no exfoliation occurred, and the XRD data show the peaks for $\mathrm{Sb}$-doped $\mathrm{SnO}_{2}$ and those of $\mathrm{Sb}_{2} \mathrm{O}_{3}$. When the $\mathrm{pH}$ of the dipping solution is increased, the white precipitate of unknown materials formed on the surface of the coating, which may be the metal hydroxides of hydrated oxides. Therefore, the suitable $\mathrm{pH}$ value of the solution for dipping will be around 1-1.2.

\subsection{Electrical Volume Resistivity of the Coating. The incor-} poration of the $\mathrm{Sb}$ oxide on to the $\mathrm{Sn}$ oxide has been confirmed by the investigation of the resistivity of the coating at various contents of $\mathrm{Sb}$ in the dipping solution. The results of the study and the influence of the $\mathrm{Sb}$ content in the solution on the resistivity of the coating are shown in Figure 5.

Figure 5 shows that the coating of $\mathrm{SnO}_{2}$ can be formed on the surface of the substrate; however, the resistivity is very high (about $2200 \Omega / \mathrm{cm}$ ) due to the electricity isolation behavior of $\mathrm{SnO}_{2}$.

When adding $\mathrm{Sb}$ into the dipping solution, the coating of $\mathrm{SnO}_{2}$ containing $\mathrm{Sb}$ will be formed with the charge difference of $\mathrm{Sn}$ and $\mathrm{Sb}$, and the resistivity of the coating will become much lower. Depending on the content of $\mathrm{Sb}$ replaced by $\mathrm{Sn}$ in the coating, the resistivity may be improved in a wide range. For example, when the Sb content in 


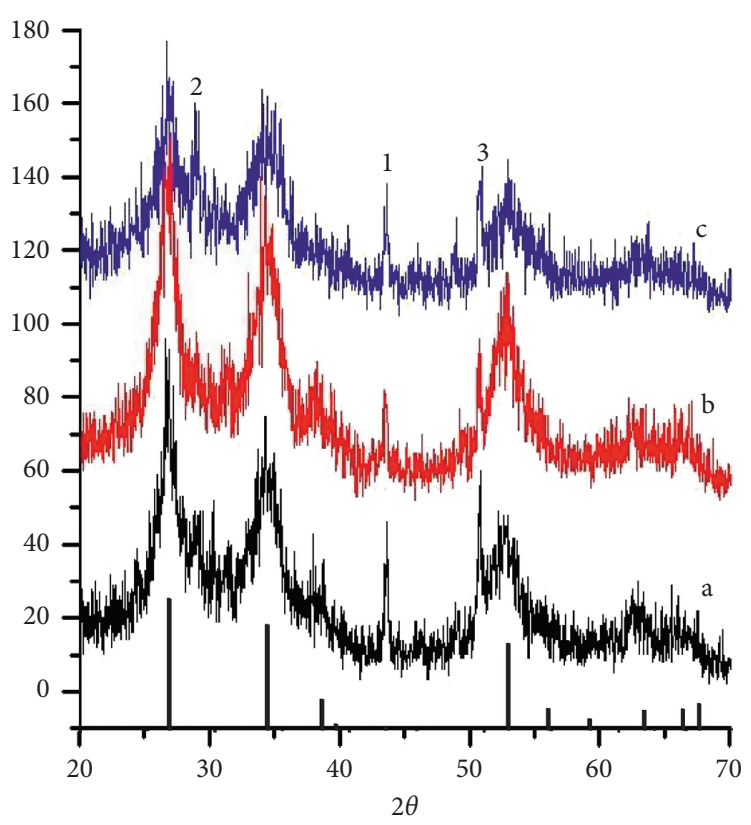

Figure 4: $\mathrm{XRD}$ patterns of $\mathrm{SnO}_{2}$-doped $\mathrm{Sb}$ thin films on 316L stainless steel at different $\mathrm{pH}$ solutions. (a) $\mathrm{pH}=1.2$, (b) 1.0, and (c) 0.8. The peaks of $\mathrm{SnO}_{2}$ (adapted from [7]) are present as the vertical black bars on the bottom.

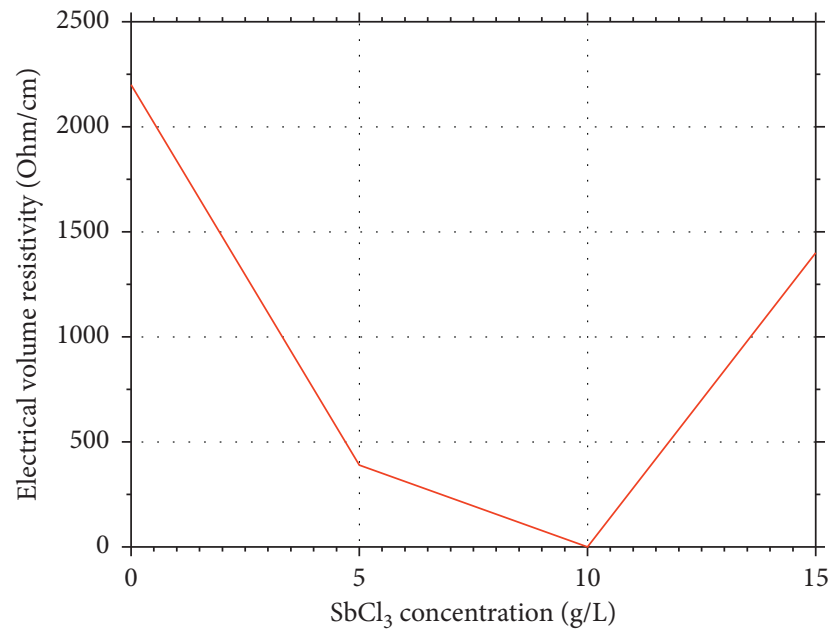

Figure 5: Electrical volume resistivity vs. Sb concentration in the reactant mixture of particles after annealing at $450^{\circ} \mathrm{C}$ for $5 \mathrm{~h}$.

the solution is $5 \%$, the resistivity of $390 \Omega / \mathrm{cm}$ is observed, the Sb content is increased to $10 \%$, and the value of $0.043 \Omega / \mathrm{cm}$ is measured. However, when the $\mathrm{Sb}$ content is further increased, the resistivity tends to be increased to the value of $1400 \Omega / \mathrm{cm}$ for the solution containing $15 \% \mathrm{SbCl}_{3}$. This is the fact that, the replacement of Sn by Sb only occurs to some levels, too high content of $\mathrm{Sb}$ in the coating may favor the formation of antimonite or antimonate rather than incorporated into the $\mathrm{SnO}_{2}$ structure. The content of $\mathrm{SbCl}_{3}$ in the dipping solution is around $10 \mathrm{~g} / \mathrm{L}$ which will give the good conductivity of the coatings.

The coating prepared in this study has very good mechanical properties. The investigation of the hardness shows that the bare substrate only has the value of $217 \mathrm{~kg} / \mathrm{mm}^{2}$, whereas one of the coatings obtains $475 \mathrm{~kg} / \mathrm{mm}^{2}$.
3.4. Application of Prepared Electrode for Treatment of Methylene Blue. The prepared coating on the 316L stainless steel has been applied as the electrode materials for the treatment of methylene blue (MB), a typical organic colorant by the electrochemical oxidation method. The cyclic voltammetry $(\mathrm{CV})$ measurement results of the solution containing $15 \mathrm{mg} / \mathrm{L}$ of $\mathrm{MB}$ and $2 \mathrm{~g} / \mathrm{L} \mathrm{Na}_{2} \mathrm{SO}_{4}$ for the $316 \mathrm{~L}$ stainless steel with and without the coating are shown in Figure 6.

The CV measurement results show that the CV behavior of the bare $316 \mathrm{~L}$ stainless steel in MB solution is very close to the one in acidic solution [8]. The high value of current density at $0.75 \mathrm{~V}$ is ascribed to breakdown of the passive film and the initiation of corrosion of the steel electrode. When the electrode is coated with mixed oxide, the $\mathrm{CV}$ 


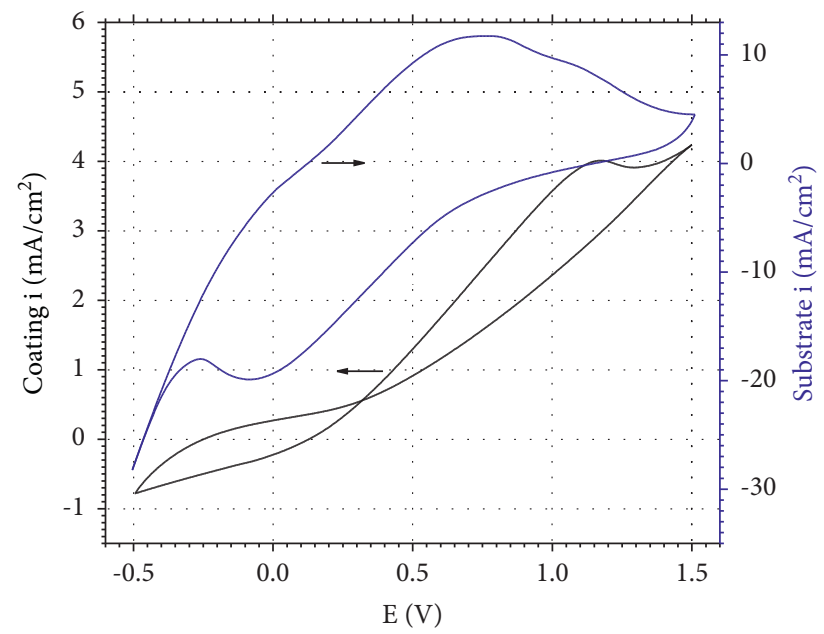

Figure 6: The cyclic voltammetry of the bare $316 \mathrm{~L}$ stainless steel (blue curve) and the $316 \mathrm{~L} / \mathrm{SnO}_{2}-\mathrm{Sb}_{2} \mathrm{O}_{3}$ (black curve) electrodes in solution containing $\mathrm{MB} 15 \mathrm{mg} / \mathrm{L}$ (with $2 \mathrm{~g} / \mathrm{L} \mathrm{Na}_{2} \mathrm{SO}_{4}$ ).

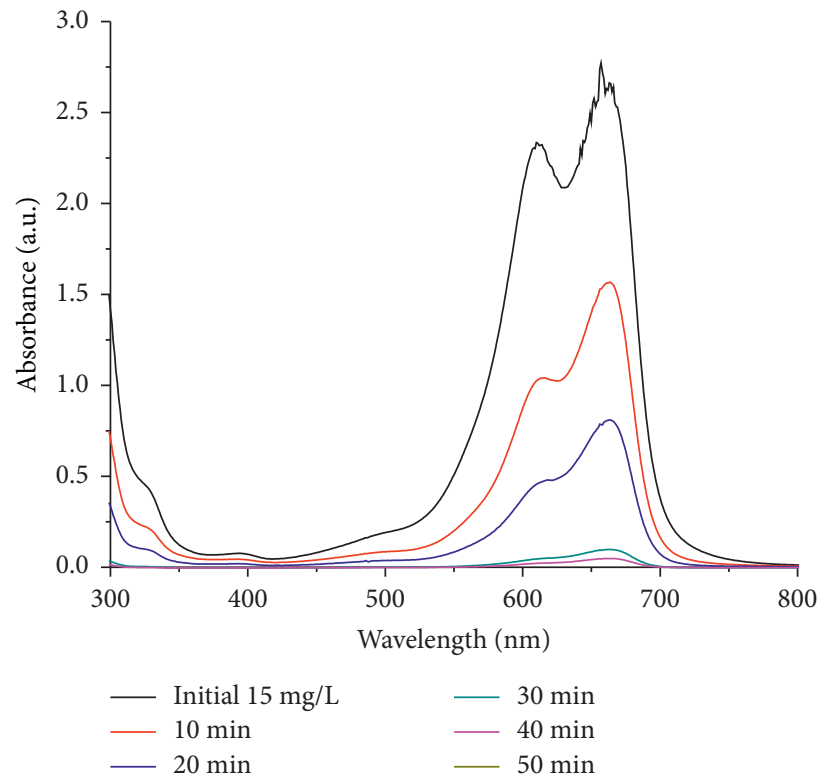

Figure 7: UV-Vis spectra of MB solution at different electrolysis time.

TABLE 1: Effect of electrolysis time on MB discoloration efficiency.

\begin{tabular}{lccccc}
\hline Electrolysis duration (min) & 10 & 20 & 30 & 50 & 50 \\
\hline Discoloration efficiency (\%) & 51.28 & 76.84 & 97.84 & 99.08 & 99.97 \\
\hline
\end{tabular}

measurement shows an oxidation peak at the potential of $1.18 \mathrm{~V}$ with the oxidation current of $4.01 \mathrm{~mA} / \mathrm{cm}^{2}$ during the treatment of $\mathrm{MB}$. The low current density is obtained due to the ionic conductivity behavior of the mixed oxide. However, the oxidation peak is rather broad, probably due to the oxidation of MB may be undergone several steps with the formation of some intermediates, and then, the intermediates are also oxidized to final products as shown in other works [9].
For evaluation of the MB treatment, the UV-Vis spectra of the initial and treated solution vs. duration of electrolysis are shown in Figure 7, and $\mathrm{MB}$ discoloration efficiency is given in Table 1.

The results of UV-Vis absorption measurement show that the spectra are corresponding to the one of $\mathrm{MB}$ which agrees well with the results in other works and the intermediates, if any, have not detected in the measured range [10]. The content of MB decreased sharply when electrolysis 
occurred as indicated by the discoloration efficiency which is calculated from the relative peak area ratio. After about 30 min, more than $90 \%$ of the original MB has been treated, and the color of the treated solution becomes pale blue. After 50 min of electrolysis, $99.97 \%$ of MB has been decomposed, and the solution becomes almost colorless. This experiment indicated that the coating on $316 \mathrm{~L}$ stainless steel can be used as the electrode for the treatment of a variety of colorants or dyes in water treatment.

\section{Conclusions}

The coatings containing antimony-doped tin oxide on $316 \mathrm{~L}$ stainless steel have been prepared and structurally characterized XRD, SEM, and CV data measurement. The impregnation of the substrate into the solution contains $\mathrm{Sb}^{3+}$ and $\mathrm{Sn}^{4+}$ ions with the concentration of $\mathrm{SbCl}_{3}$ about $10 \mathrm{~g} / \mathrm{L}$, and the $\mathrm{pH}$ in the range of 1-1.2; then, annealing at temperature of $450^{\circ} \mathrm{C}$ can avoid crack-mud phenomena in the preparation of the electrode materials. The prepared electrodes can be used as anode for the electrochemical system in the treatment of organic colorants such as methylene blue or other similar ones. The study on the treatment of $\mathrm{MB}$ in solution shows that most of $\mathrm{MB}$ has been destroyed within one hour. The fast and complete oxidation of the organic colorants will give a great chance for their application as advanced materials in water treatment.

\section{Data Availability}

No data were used to support this study.

\section{Conflicts of Interest}

The authors declare that they have no conflicts of interest.

\section{Acknowledgments}

The authors thank the National University of Civil Engineering for finance support via the 26-2019/KHXD-TD project.

\section{References}

[1] A. N. Subba Rao and V. T. Venkatarangaiah, "Metal oxidecoated anodes in wastewater treatment," Environmental Science and Pollution Research, vol. 21, no. 5, pp. 3197-3217, 2014.

[2] F. Montilla, E. Morallón, A. De Battisti, and J. L. Vázquez, "Preparation and characterization of antimony-doped tin dioxide electrodes. Part 1. Electrochemical characterization," The Journal of Physical Chemistry B, vol. 108, no. 16, pp. 5036-5043, 2004.

[3] D. Shao, X. Li, H. Xu, and W. Yan, "An improved stable Ti/Sb$\mathrm{SnO} 2$ electrode with high performance in electrochemical oxidation processes," RSC Advances, vol. 4, no. 41, pp. 21230-21237, 2014.

[4] F. Cao, J. Tan, S. Zhang, H. Wang, C. Yao, and Y. Li, "Preparation and recent developments of $\mathrm{Ti} / \mathrm{SnO}_{2}-\mathrm{Sb}$ electrodes," Journal of Chemistry, vol. 2021, Article ID 2107939, 13 pages, 2021.
[5] C. Zhou, Y. Wang, J. Chen, and J. Niu, "Porous Ti/SnO2-Sb anode as reactive electrochemical membrane for removing trace antiretroviral drug stavudine from wastewater," Environment International, vol. 133, Article ID 105157, 2019.

[6] L. Salgado, C. B. Pozos, T. Zayas, and L. Galicia, "Preparation and characterization of $\mathrm{Ti} / \mathrm{SnO}_{2}$-Sb electrodes without or with a platinum interlayer using the polymeric precursor method and thermal decomposition," International Journal of Electrochemical Science, vol. 14, pp. 7281-7292, 2019.

[7] Y. I. Kim, M. J. Jung, and K. H. Kim, “Application of inverse pole figure to Rietveld Refinement: III. Rietveld Refinement of $\mathrm{SnO}_{2}$ thin film using X-ray diffraction data," Korean Journal of Ceramics, vol. 6, pp. 354-358, 2000.

[8] Y. A. Albrimi, A. Eddib, J. Douch, Y. Berghoute, M. Hamdani, and R. M. Souto, "Electrochemical behaviour of AISI 316 austenitic stainless steel in acidic media containing chloride ions," International Journal of Electrochemical Science, vol. 6, pp. 4614-4627, 2011.

[9] M. R. Samarghandi, A. Dargahi, A. Shabanloo et al., "Electrochemical degradation of methylene blue dye using a graphite doped $\mathrm{PbO} 2$ anode: optimization of operational parameters, degradation pathway and improving the biodegradability of textile wastewater," Arabian Journal of Chemistry, vol. 13, no. 8, pp. 6847-6864, 2020.

[10] A. Baddouh, M. M. Rguiti, B. E. Ibrahimi et al., "Anodic oxidation of methylene blue dye from aqueous solution using $\mathrm{SnO}_{2}$ electrode," Iranian journal of chemistry and chemical engineering, vol. 38, pp. 175-184, 2019. 